\title{
Genetic basis for lentil adaptation to summer cropping in northern temperate environments
}

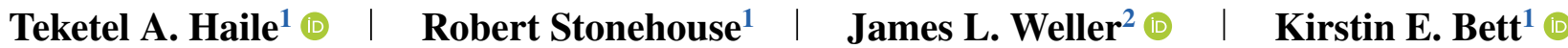

${ }^{1}$ Dep. of Plant Sciences, Univ. of

Saskatchewan, Saskatoon, SK, Canada

${ }^{2}$ School of Natural Sciences, Univ. of

Tasmania, Hobart, TAS, Australia

Correspondence

Kirstin E. Bett, Dep. of Plant Sciences, Univ. of Saskatchewan, Saskatoon, SK, Canada.

Email:k.bett@usask.ca

Assigned to Associate Editor Fanjiang Kong.

\begin{abstract}
The continued success of lentil (Lens culinaris Medik.) genetic improvement relies on the availability of broad genetic diversity, and new alleles need to be identified and incorporated into the cultivated gene pool. Availability of robust and predictive markers greatly enhances the precise transfer of genomic regions from unadapted germplasm. Quantitative trait loci (QTL) for key phenological traits in lentil were located using a recombinant inbreed line (RIL) population derived from a cross between an Ethiopian landrace (ILL 1704) and a northern temperate cultivar (CDC Robin). Field experiments were conducted at Sutherland research farm in Saskatoon and at Rosthern, Saskatchewan, Canada during 2018 and 2019. A linkage map was constructed using 21,634 single nucleotide polymorphisms (SNPs) located on seven linkage groups (LGs), which correspond to the seven haploid chromosomes of lentil. Eight QTL were identified for six phenological traits. Flowering-related QTL were identified at two regions on LG6. FLOWERING LOCUS T (FT) genes were annotated within the flowering time QTL interval based on the lentil reference genome. Similarly, a major QTL for postflowering developmental processes was located on LG5 with several senescence-associated genes annotated within the QTL interval. The flowering time QTL was validated in a different genetic background indicating the potential use of the identified markers for marker-assisted selection to precisely transfer genomic regions from exotic germplasm into elite crop cultivars without disrupting adaptation.
\end{abstract}

\section{1 | INTRODUCTION}

Lentil (Lens culinaris Medik.) is a cool-season food legume that plays a major role in alleviating food and nutritional inse-

Abbreviations: DTF, days to flowering; DTM, days to maturity; DTS, days to swollen pods; DTT, days to elongated tendrils; GEI, genotype $\times$ environment interaction; KASP, Kompetitive allele-specific PCR; LG, linkage group; QTL, quantitative trait loci; REP, reproductive period; RIL, recombinant inbreed line; SNP, single nucleotide polymorphism; VEG, vegetative period. curity. It also has significant agroecological value through its capacity for symbiotic fixation of atmospheric nitrogen and its contribution to management of pests and herbicide residue when grown in crop rotations. In 2019, lentil was produced in over 40 countries on over 4.8 million ha globally (FAO, 2020). The top five lentil producing countries in 2019 were Canada, India, Australia, Turkey, and Nepal, with Canada being both the leading producer and exporter of lentil in the world (FAO, 2020). The increasing global demand for healthier, legumebased diets requires the continual development of widely 
adapted and higher-yielding cultivars for diverse ecologies. Plant breeders often rely on elite breeding lines and cultivars for crossing because using unadapted germplasm may also introduce undesirable alleles, disrupting favorable allele combinations that have been fixed through several cycles of breeding. In many crops, elite breeding materials were derived from few founder lines and already have a narrow genetic base. Improvement of cultivars through conventional breeding techniques of selection-recombination-selection may stagnate if it is based on this narrow genetic diversity. The genetic diversity of modern lentil cultivars is relatively narrow compared with the diversity within the species and its wild relatives (Ahmad et al., 1996; Khazaei et al., 2016). Introducing new genetic variation from exotic sources is a crucial step to broaden the genetic base of modern lentil cultivars and to overcome challenges from new biotic and abiotic stresses.

Lentil originated in the Fertile Crescent of the Near East, which still harbors rich genetic diversity for both the cultivated primitive forms and wild relatives (Fratini et al., 2014; Lombardi et al., 2014). The spread of lentil from its center of origin to other parts of the world has been accompanied by the selection of traits that play a major role in adaptation to new agroecological zones (Materne \& Siddique, 2009). Flowering, the transition from vegetative to reproductive stage, is one of the most important factors that determine the adaptation of plants to new environments. Other developmental processes, such as stem elongation, apical dominance, lateral branching, resource allocation, maturity, and yield, also accompany this transition (Weller \& Ortega, 2015). Genes and environmental factors that affect the initial flowering transition can also influence postflowering processes affecting fertility and pod development (Weller \& Ortega, 2015). Lentil has a requirement of exposure to specific photoperiods and temperatures to flower, and flowering may be significantly delayed or prevented if these requirements are not met (Roberts et al., 1986; Summerfield et al., 1985a; Summerfield et al., 1985b; Wright et al., 2021). Lentils have been selected for adaptations to three major climatic regions of the world: Mediterranean, subtropical savannah (south Asia), and northern temperate (Materne \& Siddique, 2009; Tullu et al., 2011). In Mediterranean-type environments, lentils are generally sown after the autumn rains and emerge into cool temperatures and short days, but vegetative crops experience progressively lengthening days and warming temperatures. In subtropical savannah environments, lentils are sown during the winter months and emerge into short days and cooler temperatures, but the temperature gradually rises during the reproductive phase. In northern temperate environments, such as central Canada, lentil is usually seeded in the spring and plants grow and flower under long days and when temperatures are optimum. When germplasm from winter production regions is grown in northern temperate environments, flowering often

\section{Core Ideas}

- Stable QTL were located for key phenological traits in lentil that lead to regional adaptation.

- $F T$ genes are candidates for controlling flowering time in lentil grown in temperate environments.

- Major QTL controlling postflowering development contained several senescence-associated genes.

- Markers identified could be used to minimize disruption to adaptation when using exotic germplasm.

occurs too early, before plants can accumulate the vegetative growth necessary to maximize their yield potential.

Identifying the genetic basis for flowering is crucial to develop genomic tools that will accelerate and enhance the precision of introducing new genetic variability from diverse germplasm. Several flowering-time genes that regulate the transition from vegetative to reproductive phase have been reported in crop and model legumes (Nelson et al., 2010; Weller \& Ortega, 2015; Weller et al., 2012). This transition is triggered by environmental cues as well as endogenous signals such as developmental stage, hormones, and carbohydrate levels (Amasino \& Michaels, 2010; Hecht et al., 2005). Light, through its effect on daylength, light quality, and temperature, through vernalization and ambient temperature effects, are the main environmental regulators of flowering (Hecht et al., 2005). Endogenous pathways function independently of environmental signals and are related to the developmental state of the plant (Amasino \& Michaels, 2010). In Arabidopsis [Arabidopsis thaliana (L.) Heynh.], several genes influence the flowering process, with varied roles in photoperception, circadian clock function, photoperiod response, vernalization response, autonomous flowering, and integration of flowering pathway signals (Andrés \& Coupland, 2012; Fowler et al., 1999; Imaizumi et al., 2003; Kardailsky et al., 1999; Kobayashi et al., 1999; Putterill et al., 1995; Searle et al., 2006; Simpson, 2004; Suárez-López et al., 2001). Many of these genes are shown to be conserved across legume crop species although several gene families have undergone differential gene loss or expansion (Hecht et al., 2005). For example, $\sim 20$ loci associated with flowering time have been reported in pea (Pisum sativum L.) and soybean [Glycine max (L.) Merr.] (Lin et al., 2021; Weller \& Ortega, 2015). In chickpea (Cicer arietinum L.), four major genes involved in the control of flowering time have been identified (Gaur et al., 2015; Hegde, 2010; Kumar \& van Rheenen, 2000). In lentil, Sarker et al. (1999) demonstrated the control of flowering time by the major locus $S n$, which was 
subsequently identified as an ELF3 ortholog (Weller et al., 2012). Beyond this, the genetic control of flowering time in lentil is not well understood. Several studies have reported flowering time quantitative trait loci (QTL) using intraspecific crosses (Fedoruk et al., 2013; Kahriman et al., 2015; Tullu et al., 2008) and interspecific crosses (Fratini et al., 2007; Polanco et al., 2019), but there is a notable lack of information on genetic differences that underlie major regional adaptations within the crop species. In this study, we used a recombinant inbred line (RIL) population developed from a cross between an exotic accession and adapted cultivar to identify regions of the lentil genome associated with key phenological traits. The availability of molecular markers for these loci is crucial for marker-assisted breeding and the effective use of broader lentil genetic resources in a breeding program.

\section{2 | MATERIALS AND METHODS}

\section{1 | Plant materials and phenotyping}

A population of 110 RILs, LR-01, was available from a cross between ILL 1704 and 'CDC Robin'. CDC Robin is a lentil cultivar developed at the University of Saskatchewan (Vandenberg et al., 2002), and ILL 1704 is a landrace from Ethiopia. ILL 1704 was selected to represent the Mediterranean and northeast African lentil accessions. The RILs and parental lines were grown at Sutherland $\left(52^{\circ} 10^{\prime} \mathrm{N}, 106^{\circ} 30^{\prime}\right.$ W) and Rosthern $\left(52^{\circ} 41^{\prime} \mathrm{N}, 106^{\circ} 17^{\prime} \mathrm{W}\right)$, Saskatchewan, in 2018 and 2019. All field plots were seeded between late April and mid-May with a target sowing density of 100 seeds $\mathrm{m}^{2}$. The field trials were established in $1 \mathrm{~m}^{2}$ three-row microplots arranged in randomized complete block design with three replications in each site-year. Days to elongated tendrils (DTT), days to flowering (DTF), days to swollen pods (DTS), and days to maturity (DTM) were recorded in both years. Values for DTT, DTF, and DTS were recorded as the number of days from sowing to when $10 \%$ of plants in a plot had elongated tendrils, at least one open flower, and pods with fully swollen seeds, respectively. Days to maturity was recorded as the date when $10 \%$ of plants displayed $50 \%$ pod maturity. Vegetative (VEG) and reproductive (REP) periods were recorded as the number of days from emergence to flowering and from flowering to maturity, respectively.

The phenotypic data were analyzed using analysis of variance with SAS mixed models, v9.4 (Littell et al., 2006). The data were first analyzed separately in each environment (site-year) and then combined across environments. Genotype was considered a fixed effect and replication was considered random for data analysis in each environment. For combined data analyses, replication nested in environment, environment, and genotype $\times$ environment interaction (GEI) were considered random effects. The Kenward-Roger degrees of freedom approximation method was used to compute the degrees of freedom for means (Kenward \& Roger, 1997). Broad-sense heritability $\left(H^{2}\right)$ on a plot basis was estimated for all traits using the following equation:

$$
\frac{\sigma_{\mathrm{g}}^{2}}{\sigma_{\mathrm{g}}^{2}+\frac{\sigma_{\mathrm{ge}}^{2}}{e}+\frac{\sigma_{\varepsilon}^{2}}{r e}}
$$

where $\sigma_{\mathrm{g}}^{2}$ is the genetic variance, $\sigma_{\mathrm{ge}}^{2}$ is the GEI variance, $\sigma_{\varepsilon}^{2}$ is the residual variance, $e$ is the number of environments, and $r$ is the number of replications per environment. Variance components were estimated in SAS using restricted maximum likelihood method described in Holland et al. (2003) with the effect of genotype, environment, GEI, and replication considered as random effect.

\section{2 | Genotyping and QTL mapping}

Genomic DNA was extracted from fresh leaves of 2 to 3wk-old seedlings for all lines using a Qiagen MiniPrep Kit (Qiagen). Genotyping of all lines was performed using a custom lentil exome capture assay as described in Ogutcen et al. (2018). Markers with a minor allele frequency $>5 \%$ and missing proportion $<10 \%$ were used for linkage mapping. Markers showing significant segregation distortion (deviating from the expected 1:1 ratio for the RILs) based on a chi-square $\left(\chi^{2}\right)$ test were removed from the analysis. We used a Perl pipeline, SimpleMap (Jighly et al., 2015), with a repulsion threshold of zero to check the number of recombination events for each pair of markers and to keep only one representative marker for pairs with no recombination. The reduced subset of representative markers was used for linkage mapping and redundant markers excluded at the first step were realigned to the map after linkage map construction (Jighly et al., 2015). Markers were clustered into linkage groups (LGs) using the MSTMap software (Wu et al., 2008), with a $p$ value of $1 \times 10^{-15}$ and a maximum distance between markers of $15 \mathrm{cM}$. The relative order of markers within each LG was determined using the MapDisto v2.1.7.3 software (Lorieux, 2012), with a logarithm of the odds threshold of 3 and a cut off recombination value of 0.3 . Distances between markers were calculated using the Kosambi function (Kosambi, 1943). The order of markers in each LG was refined using 'AutoCheckInversions' and 'AutoRipple' commands in MapDisto. Linkage groups were corrected for double recombinants using the "color genotypes' window in MapDisto. Linkage groups were assigned to each chromosome based on their marker locations on the lentil reference genome (CDC Redberry genome assembly v2.0) (Ramsay et al., 2021).

Quantitative trait loci analysis was performed using Windows QTL Cartographer v2.5 (Wang et al., 2012). Composite 
TA B L E $1 \quad P$ values from mixed model analysis of variance $F$ test for six phonological traits

\begin{tabular}{|c|c|c|c|c|c|c|}
\hline Effect & DTT & VEG & DTF & REP & DTM & DTS \\
\hline Genotype & $* * *$ & $* * *$ & $* * *$ & $* * *$ & $* * *$ & $* * *$ \\
\hline Environment & $\mathrm{NS}^{\dagger}$ & NS & NS & NS & NS & NS \\
\hline Genotype $\times$ environment & $* * *$ & $* * *$ & $* * *$ & $* * *$ & $* * *$ & $* * *$ \\
\hline $\mathrm{CV} \%$ & 15.4 & 9.8 & 11.7 & 17.9 & 10.6 & 9.8 \\
\hline
\end{tabular}

Note. DTT, days to elongated tendrils; VEG, vegetative period; DTF, days to flowering; REP, reproductive period; DTM, days to maturity; DTS, days to swollen pods.

*Significant at the .05 probability level.

*** Significant at the .001 probability level.

${ }^{\dagger} \mathrm{NS}$, nonsignificant.

interval mapping (CIM) was implemented with a 2-cM walk speed, which was performed on the LS-means of each trait for individual environment and averaged (combined) across all environments. Cofactor selection was performed using forward and backward regression with a significance level of $P=$ .1 with a 10 -cM window size. The QTL significance thresholds were determined based on 1,000 permutations at a significance level of $P=.05$. Candidate genes within the identified QTL intervals were retrieved using the lentil reference genome (Ramsay et al., 2021).

\section{3 | QTL validation}

A total of $286 \mathrm{~F}_{2}$ lines were developed from a cross between 'CDC Redberry' and ILL 1704. CDC Redberry is a lentil cultivar developed at the University of Saskatchewan (Vandenberg et al., 2006) and the genotype used for the reference assembly of the lentil genome. Both CDC Redberry and CDC Robin are adapted to northern temperate environments and share the same phenology characteristics; therefore, CDC Redberry is an acceptable alternative to CDC Robin for validating the identified QTL. In 2018, the $286 \mathrm{~F}_{2}$ lines and the two parents were grown at the Seed Farm of the Crop Development Centre, University of Saskatchewan $\left(52^{\circ} 8^{\prime} \mathrm{N}\right.$, $106^{\circ} 37^{\prime} \mathrm{W}$ ). Each line was grown in 1.5 -L pots. Leaf tissues were collected from each 4 to 6 -wk-old seedling and plants were allowed to produce $\mathrm{F}_{3}$ seed. DNA was extracted using methods described above. In 2019, the resulting $\mathrm{F}_{2}$-derived $\mathrm{F}_{3}$ generations were grown as single 1-m rows at Sutherland adjacent to the LR-01 population. The field experiments were arranged in two blocks each containing 51 plots. CDC Redberry, ILL 1704, 'CDC Kermit', and 'CDC Maxim' were grown as replicated checks. The field trials were established in $1-\mathrm{m}^{2}$, three-row microplots arranged in an augmented randomized complete block design, where the four check cultivars were randomly assigned to rows of plots within a block and unreplicated entries were randomly arranged in the remaining rows (Federer, 1961). Values for DTT, VEG,
DTF, REP, DTM, and DTS were recorded as described above. The phenotypic data were analyzed using analysis of variance with SAS Mixed models, v9.4 (Littell et al., 2006). Genotypes (entries plus check cultivars) were considered as fixed effect and block was considered as a random effect. Trait values of entries were adjusted relative to the check cultivars replicated in each block using the LSMEANS procedure in SAS (Wolfinger et al., 1997).

A total of eight single nucleotide polymorphisms (SNPs) within the coding sequences of FTb, FTa1, FTa2, and FTc located in the flowering time QTL intervals were chosen for validation (Supplemental Table S1). Two allele-specific forward primers and a reverse primer were designed for use in fluorescence-based Kompetitive allele-specific PCR (KASP) assays (LGC Biosearch Technologies). DNA from the 286 lines was assayed using these primers and KASP reaction mix (LGC Biosearch Technologies) according to manufacturer's instructions. The PCR amplification was carried out in a CFX384 Real-Time PCR System (Bio-Rad), and endproduct fluorescence readings were analysed using CFX Manager Software v3.1 (Bio-Rad).

\section{3 | RESULTS}

\section{1 | Phenotypic data}

Analysis of variance on combined data across environments revealed significant variation among the RILs for all measured traits (Table 1). There was no effect of the environment but the interaction of genotype with the environment was significant, indicating variable performance of lentil genotypes across the four environments.

Frequency distribution of traits for the RILs and means of the parental lines are shown in Figure 1. The distribution of traits followed an approximately normal distribution except for DTT and VEG at Sutherland in both years, VEG and DTF at Rosthern in 2019, DTF at Sutherland in 2018, REP and DTS at both locations in 2018, which were slightly skewed 

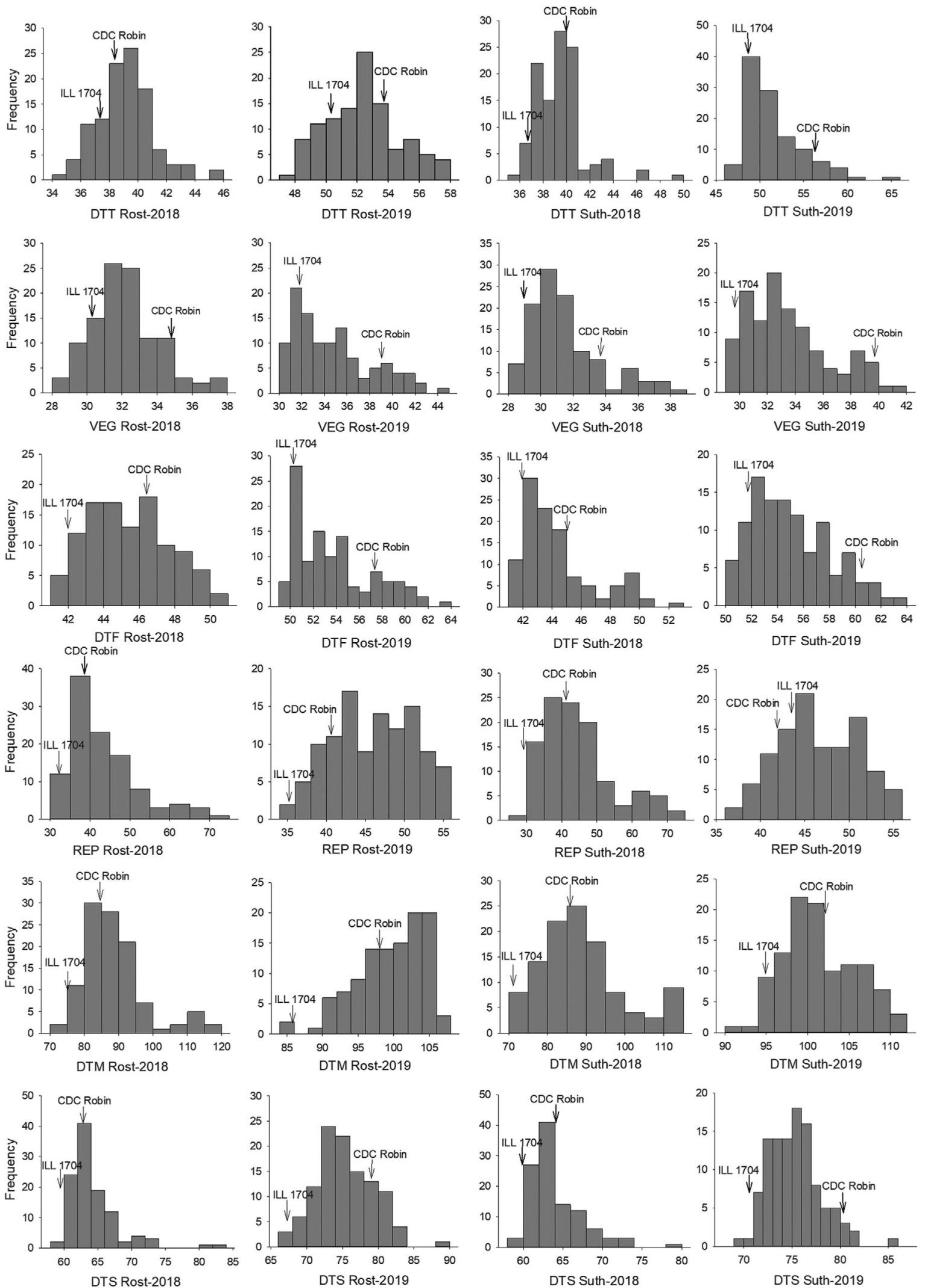

F I G U R E 1 Frequency distribution of recombinant inbred lines and the two parents in the LR-01 population for days to elongated tendrils (DTT), vegetative period (VEG), days to flowering (DTF), reproductive period (REP), days to maturity (DTM), and days to swollen pods (DTS) measured at Rosthern (Rost) and Sutherland (Suth) in 2018 and 2019. The mean values of the parents are indicated with an arrow 
T A B L E 2 Pearson's correlation coefficients among six phenological traits for each environment

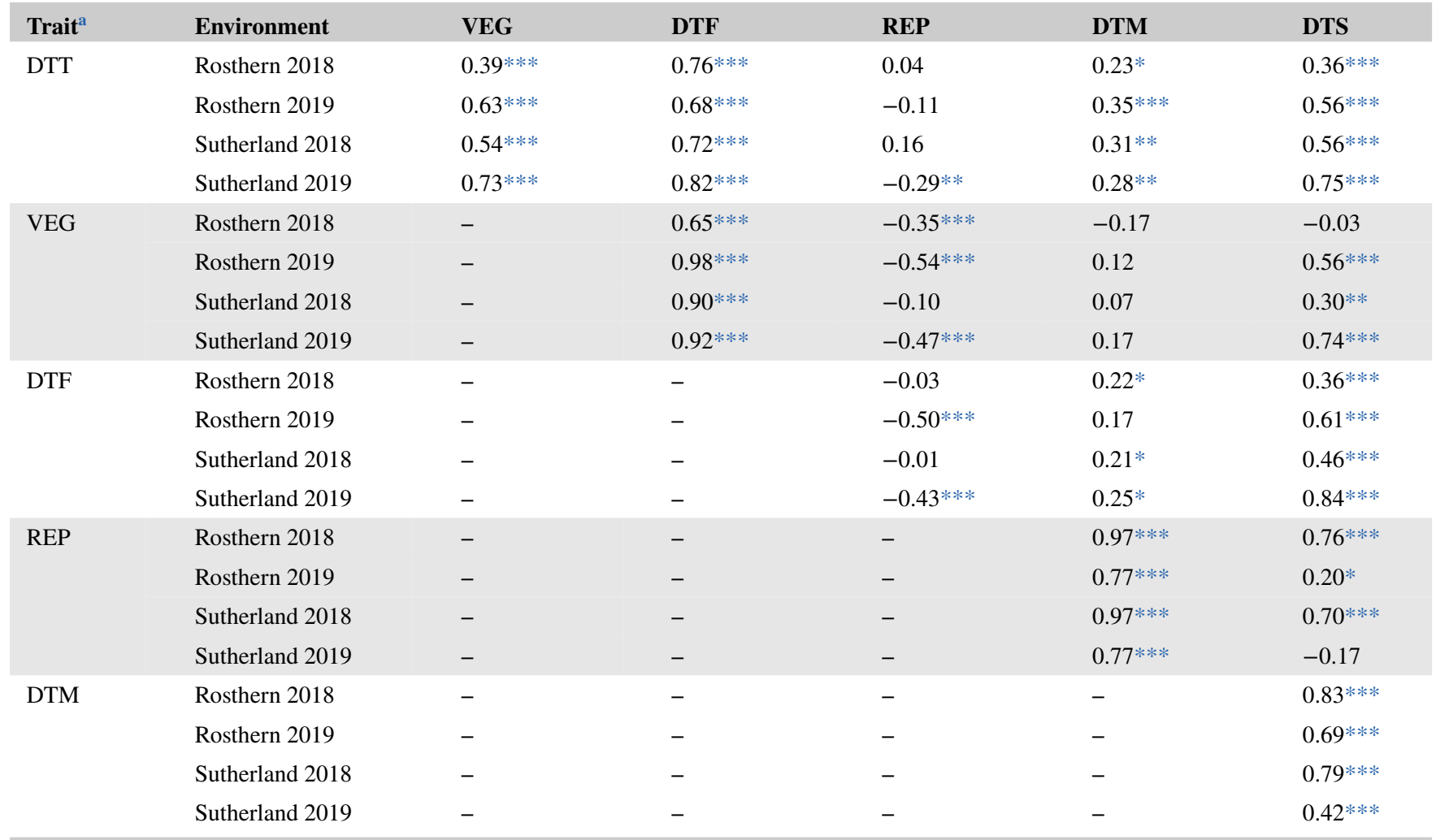

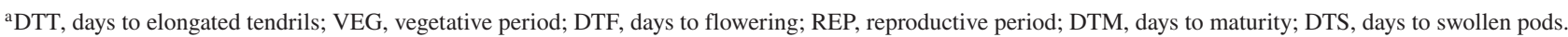

*Significant at the .05 probability level.

** Significant at the .01 probability level.

*** Significant at the .001 probability level.

toward higher values, and DTM at Rosthern in 2019, which was skewed toward lower values (Figure 1). As expected, ILL 1704 flowered and matured earlier than CDC Robin in all environments. ILL 1704 and CDC Robin differed in DTF by $4-9 \mathrm{~d}$ and in DTM by $7-15 \mathrm{~d}$ across environments. For all traits, transgressive segregants in both directions were observed in all environments (Figure 1).

A considerable number of late transgressive segregants and very few early segregants were observed for DTM, REP, and DTS across environments. As these are essentially maturity rather than flowering traits it is likely that they are subject to more complex physiological and genetic control, exposing greater potential for the emergence of novel genotype combinations impairing maturity in some way. The two locations were more or less similar with respect to the performance of lines but there were slight differences between the years. In 2018, DTT ranged from 34 to $49 \mathrm{~d}$ across locations but it was delayed by up to two wk in 2019. The VEG period was also delayed by up to $1 \mathrm{wk}$ in 2019 vs. 2018. Plants flowered earlier in 2018 than in 2019 but flowering time was similar between Rosthern and Sutherland in both years. Days to flowering ranged from 41 to 52 and 49 to $63 \mathrm{~d}$ in 2018 and 2019, respectively. Although the duration of flowering was earlier in 2018, maturity of plants took longer and, as a result, REP was narrower in 2019 at both locations.

Pearson's correlation coefficients for all traits measured within each environment are shown in Table 2. There were significant positive correlations $(0.39 \leq r \leq 0.98, P<.001)$ among DTT, VEG, and DTF in all environments (Table 2). Similarly, DTM showed strong positive correlation with REP $(0.77 \leq r \leq 0.97, P<.001)$ and DTS $(0.42 \leq r \leq 0.83, P$ $<.001)$ in all environments. DTM had no correlation with VEG but showed weak positive correlations with DTT and DTF across environments. DTS was also positively correlated with DTT $(0.36 \leq r \leq 0.75, P<.001)$ and DTF $(0.36 \leq$ $r \leq 0.84, P<.001)$. On the other hand, REP showed significantly different correlations with DTT, DTF, and VEG depending on environment. This may suggest distinct genetic control of flowering and maturity traits. Moderate to high estimates of heritability were obtained for DTT (0.38), DTS (0.49), DTF (0.53), VEG (0.58), REP (0.61), and DTM (0.62). The observed phenotypic variance in these traits has a genetic cause and the data can be successfully used to identify loci controlling phenological traits in lentil. 


\section{2 | Genetic map}

The genetic map included 21,634 SNPs in seven LGs that spanned a total map distance of $1643.9 \mathrm{cM}$ (https://knowpulse.usask.ca/Geneticmap/2695342; Supplemental Table S2). Linkage groups corresponded to the seven chromosomes of lentil (Supplemental Figure S1). For QTL analysis, SNPs with redundant positions were filtered out, leaving 2,342 uniquely mapped SNPs (Supplemental Table S2). These were distributed evenly across chromosomes (from 228 in chromosome 7 to 421 in chromosome 3) with an average distance of $0.7 \mathrm{cM}$ between adjacent SNPs.

\section{3 | QTL analysis}

Quantitative trait loci were only reported if they were identified in at least two of the individual environments and in the combined data, and across the six phenological traits, only eight QTL met these criteria. Two QTL were detected each for VEG and DTF, and only one QTL each was detected for DTT, DTM, REP, and DTS (Table 3). The single QTL for REP, DTM, and DTS were localized within a common interval on LG5 (119.2-129.2 cM), whereas all remaining QTL were located within two distinct regions on LG6. The QTL for DTT (qDTT.6), VEG ( $q V E G .6-1)$, and DTF ( $q D T F .6-1)$ were located near the top of LG6 $(2.6-10.2 \mathrm{cM})$ and respectively explained $21-38,7-38$, and $19-43 \%$ of the phenotypic variance across environments (Table 3). qDTT.6 and qDTF.6-1 were colocalized, while qVEG.6-1 mapped $2 \mathrm{cM}$ away, which suggests a common genetic control for these correlated traits (Tables 2 and 3). The qDTF.6-1 QTL interval spanned a $1.7-\mathrm{Mb}$ region $(1,050,443-2,724,479 \mathrm{bp})$ in the lentil reference genome (v2.0) that harbors 25 annotated genes including two genes homologous to the Arabidopsis florigen gene FT (Lcu.2RBY.6g000730 and Lcu.2RBY.6g000760), which are directly under the QTL peak (Supplemental Table S3). Among the 585 SNPs within the qDTF.6-1 interval, 10 are in the Lcu.2RBY.6g000730 coding sequence and 11 within the Lcu.2RBY.6g000760 coding sequence (Supplemental Table S4), and these may potentially serve as suitable markers for indicating the allelic state of $q D T F .6-1$ locus. The second region in the middle of LG6 $(85.2-109.5 \mathrm{cM})$ also harbored QTL for VEG ( $q V E G .6-2)$ and DTF ( $q D T F .6-2)$ that accounted for 19-21 and 13-18\% of the variance across environments, respectively. The qDTF.6-2 interval spanned 6.4 $\mathrm{Mb}$ in the lentil reference genome and harbors 96 annotated genes including orthologs of the FTal, FTa2, and FTc genes (Supplemental Table S3). There are four, two, and six SNPs annotated within FTal, FTa2, and FTc coding sequences, respectively (Supplemental Table S4). These markers can be used to identify the allelic state of the $F T a$ and $F T c$ genes in lentil. The QTL for DTM ( $q D T M .5)$ and REP (qREP.5) explained 48 and $59 \%$ of the variance across environments, respectively. These QTL were also identified in all of the individual environments and explained 24-56 and 30-43\% of the phenotypic variance, respectively. A single QTL for DTS ( $q D T S .5$ ) was also localized with $q D T M .5$ and $q R E P .5$ that accounted for $10-20 \%$ of the variance across environments. There are 69 SNPs within this common interval, which spanned a large physical distance of $62.2 \mathrm{Mb}(356,415,824$ $418,589,260 \mathrm{bp}$ ) on the lentil reference genome. Three other SNPs from the unanchored unitig2307 were also located within this interval. There are 561 annotated genes within the confidence interval of the QTL with several potentially phenology- or senescence-associated genes (Supplemental Table S3).

\section{4 | Validation of identified QTL}

We used an $\mathrm{F}_{3}$ generation from a cross between a temperate cultivar CDC Redberry and ILL 1704 for validating the flowering time QTL identified in this study. The distribution of phenological traits for the $\mathrm{F}_{3}$ and the parental lines are shown in Figure 2. Transgressive segregants in both directions were observed for all traits. The distribution of DTT, VEG, DTF, and DTS were slightly skewed toward higher values, while DTM and REP were skewed toward lower values (Figure 2). ILL 1704 flowered $10 \mathrm{~d}$ earlier and matured $11 \mathrm{~d}$ earlier than CDC Redberry.

Two SNPs within $F T b$ coding sequence ( $q D T F .6-1$ interval) and six SNPs within FTal, FTa2, and FTc coding sequences ( $q$ DTF.6-2 interval) were converted to KASP primer and 286 lines were screened for DTF (Table 4; Supplemental Table S1). The SNPs within FTa1, FTa2, and FTc have similar haplotypes, which suggests that the three genes originated from recent duplication events (Supplemental Table S1). Student's $t$ test was performed to determine statistical significance of the difference in DTF between sets of individuals carrying the CDC Redberry and ILL 1704 alleles. Days to flowering was significantly different $(t=2.3, p=.023)$ and $(t=-2.6$, $p=.010$ ) between the two alleles for both groups of markers. At $q D T F .6-1$, the average DTF were $58.1( \pm 3.6)$ and 56.6 $( \pm 4)$ between lines carrying the CDC Redberry and ILL 1704 alleles resulting in mean difference of $1.5 \mathrm{~d}$. Similarly, mean DTF were $56.1( \pm 2.8)$ and $57.9( \pm 5.5)$ between lines carrying the CDC Redberry and ILL 1704 alleles at $q D T F .6-2$ resulting in mean difference of $1.8 \mathrm{~d}$. This suggests that the identified QTL can be useful in different genetic backgrounds involving crosses between adapted and exotic germplasm.

\section{4 | DISCUSSION}

Control of flowering time is an important factor that determines plant adaptation to a new environment. The transition 
T A B L E 3 Quantitative trait loci (QTL) identified for six phenological traits in the LR-01 population (ILL $1704 \times$ CDC Robin) evaluated across four environments. All QTL analyses were performed using data from each environment and averaged (combined) across all environments

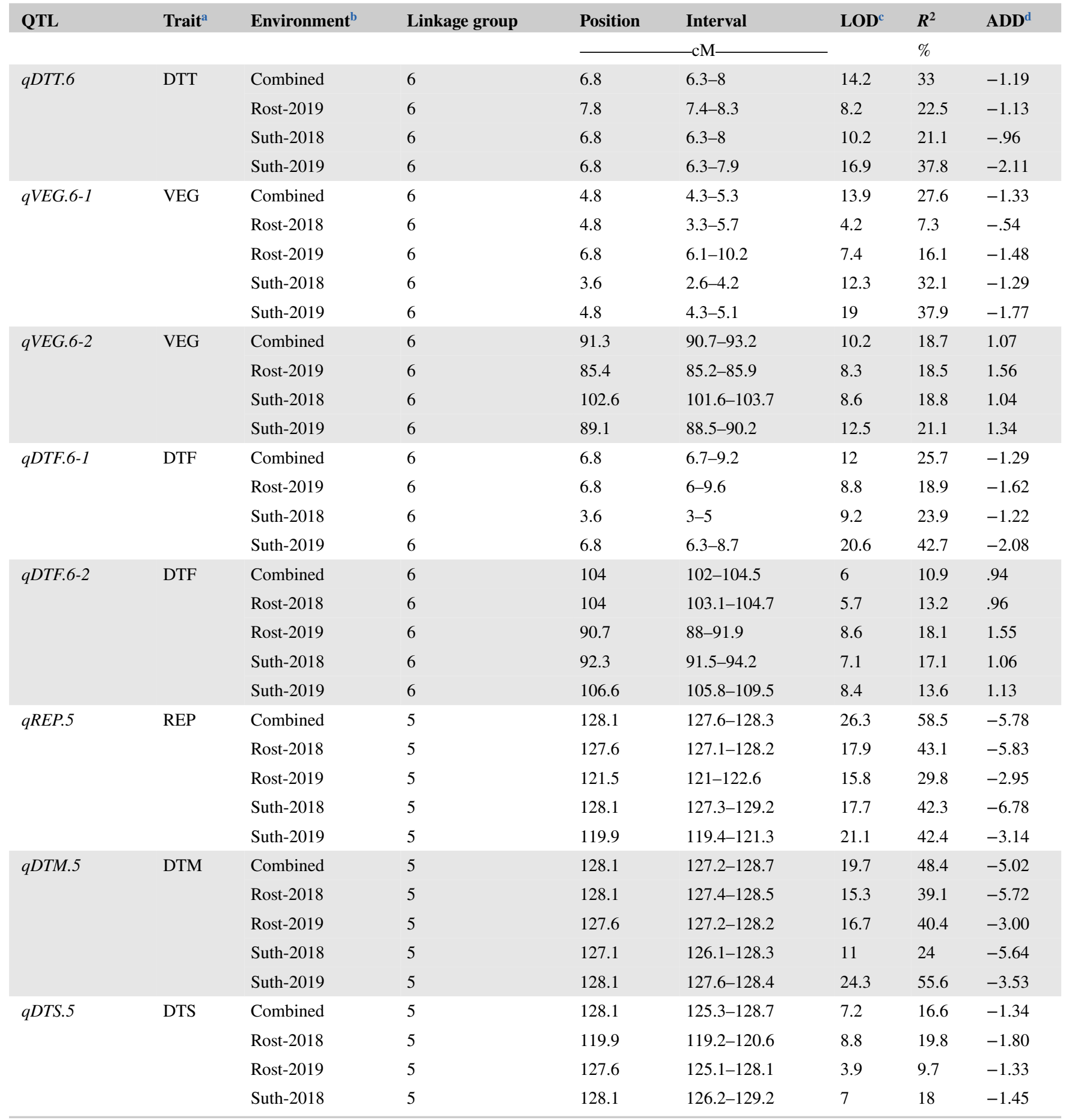

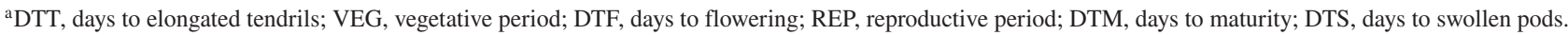
${ }^{\mathrm{b}}$ Rost, Rosthern; Suth, Sutherland.

${ }^{c} \mathrm{LOD}, \log$ arithm of the odds.

${ }^{\mathrm{d}} \mathrm{ADD}$, additive effect attributed to this locus. Negative values represent alleles originating in ILL 1704; positive values represent alleles originating from CDC Robin.

from vegetative to reproductive growth is a key developmental stage in the life of a plant, and the induction, expression, and maintenance of the flowering state are regulated by many external and endogenous factors (Hecht et al., 2005).
In winter production regions, lentil is sown during winter months and emerges into short days and cooler temperatures. In Mediterranean-type environments, vegetative plants experience lengthening days and warmer temperatures slowly as 

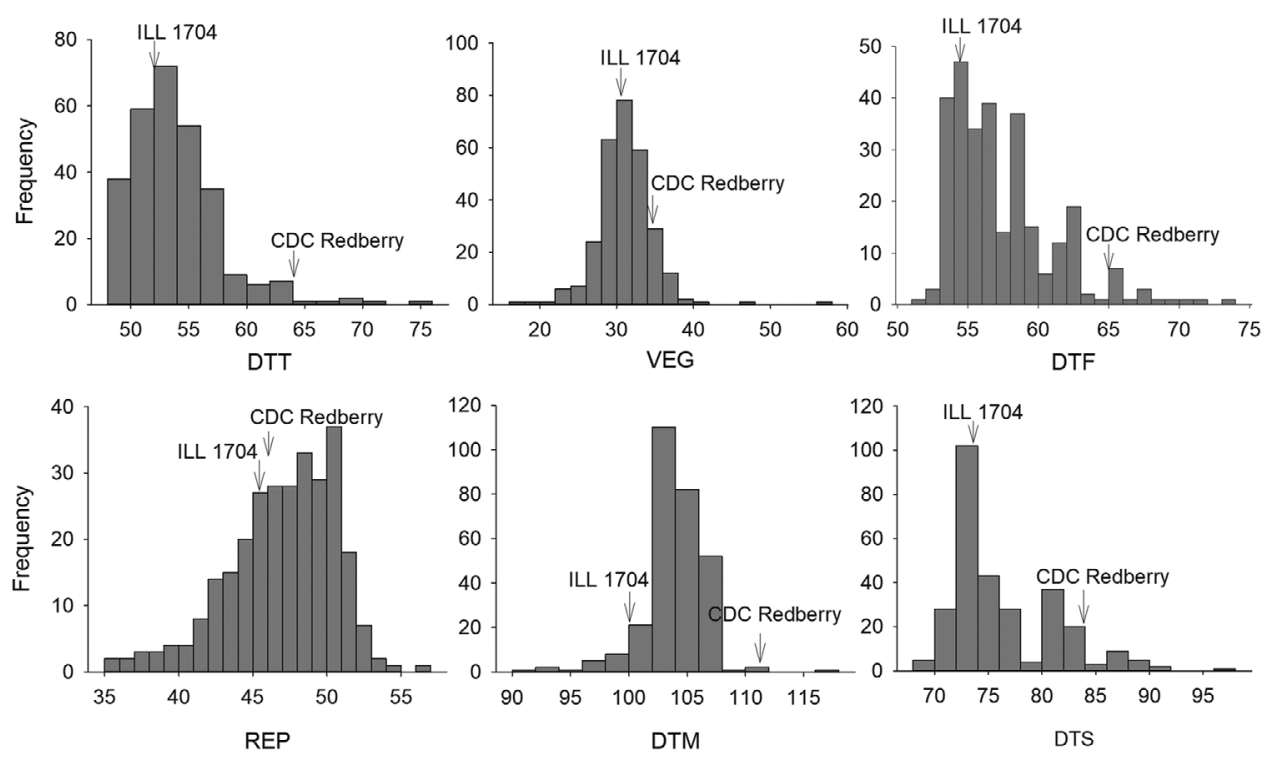

F I G U R E 2 Frequency distribution of CDC Redberry $\times$ ILL $1704 \mathrm{~F}_{3}$ population and the two parents for days to elongated tendrils (DTT), vegetative period (VEG), days to flowering (DTF), reproductive period (REP), days to maturity (DTM), and days to swollen pods (DTS). The mean values of the parents are indicated with an arrow

TA B L E 4 Markers selected for validation of the flowering time quantitative trait loci (QTL) using an $\mathrm{F}_{3}$ generation developed from CDC Redberry $\times$ ILL 1704 cross

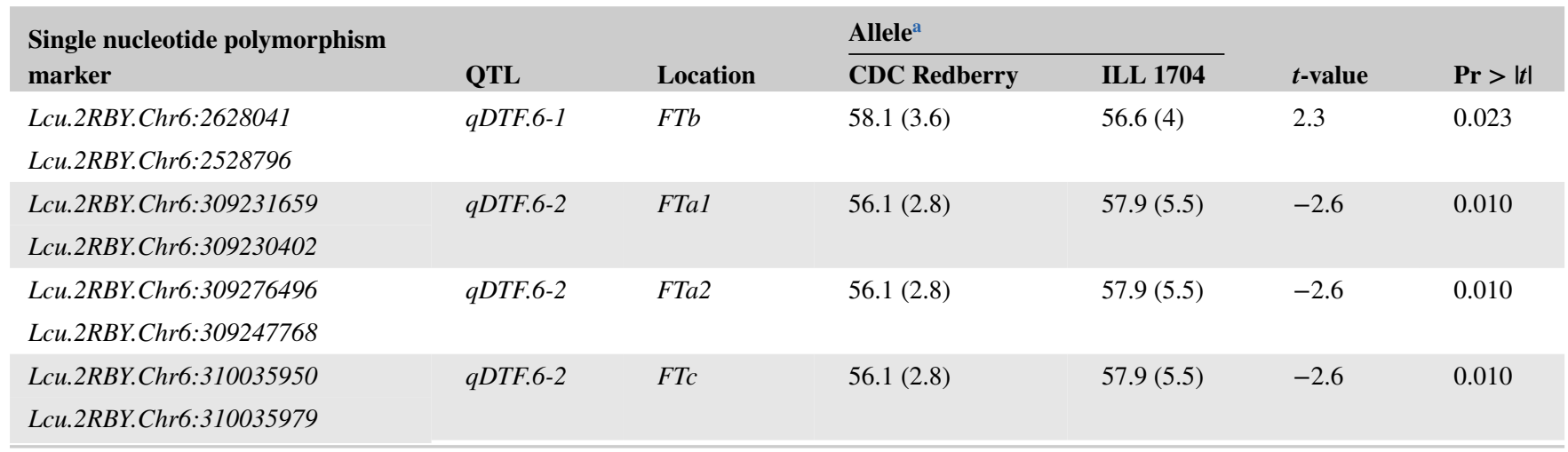

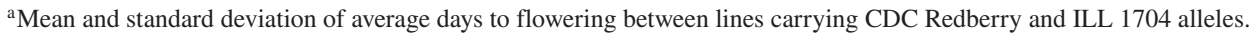

the season progresses toward spring, whereas in subtropical savannah growing environments the temperature rises toward reproductive phase, but days are short during the entire crop life cycle. When lentils from these regions are sown in northern temperate environments during the spring, they experience long days and warm temperatures shortly after germination and their photoperiodic and critical temperature requirement for flowering are met quickly. Early flowering results in short stature plants that mature prematurely leading to reduced yield. Therefore, adaptations to delay flowering until plants accumulate enough biomass are necessary to avoid a significant yield penalty. Understanding the genetic control of flowering and postflowering developmental processes is important to develop molecular tools that aid in germplasm evaluation as well as selection of adapted lines following hybridization with exotic germplasm.

We used a RIL population derived from a cross between a landrace from Ethiopia and a northern temperate cultivar to identify QTL associated with important phenological traits that lead to regional adaptations. Significant genetic variation was detected among the RILs for flowering and postflowering developmental traits at the four environments (Table 1). Major QTL controlling DTT ( $q D T T .6$ ), VEG ( $q V E G .6-1)$, and DTF ( $q D T F .6-1)$ were located near the top of LG6. This is expected because VEG is similar to DTF except that it is adjusted for days to emergence. Similarly, the development of tendrils preceded the transition from vegetative to reproductive stage and is correlated with flower initiation. As expected, the 
northern temperate cultivar contributed the positive alleles at these QTL that delayed the time to tendril development and flowering (Table 3).

The qDTF.6-1 QTL interval harbors 25 annotated genes including two genes homologous to the Arabidopsis florigen gene FT (Supplemental Table S3). In Arabidopsis, FT is expressed in phloem tissues of cotyledons and leaves under long days and encodes the hormone-like florigen protein that is transported through the phloem to the shoot apex where it promotes flowering (Abe et al., 2005; Wigge et al., 2005). The role of $F T$ genes in the integration of environmental signals for flowering has been documented in a wide range of plant species including both model and crop legumes (Kong et al., 2010; Laurie et al., 2011; Yamashino et al., 2013). Natural variation for flowering time is associated with the corresponding syntenic genomic regions in several temperate legume species (Weller \& Ortega, 2015). Papilionoid legumes have three distinct subclades of $F T$ genes-FTa, FTb, and $F T c$ - and in barrel clover (Medicago truncatula Gaertn.) and pea (Pisum sativum L.), the FTa and FTb subclades are represented by two genes each, namely FTal/a2 and FTb1/b2 (Hecht et al., 2011). In both species, FTal plays an important role controlling flowering and integrating photoperiod, vernalization, and light quality signaling, while $F T b$ genes are primarily implicated in the photoperiodic response (Hecht et al., 2011; Laurie et al., 2011). The qDTF.6-1 region is collinear with a region of barrel clover chromosome 7 previously observed to also contain the two FTb genes MtFTbl and MtFTb2 (Hecht et al., 2011), and sequence relationships confirm that the lentil genes also belong to the FTb subclade. The fact that $q D T F .6-1$ was identified under the long day growing environments in Saskatchewan is consistent with the possibility that one or both of these genes may also have a role in promoting flowering under long day conditions and show attenuated function in genotypes adapted to the Canadian summer cropping system.

The second QTL for DTF (qDTF.6-2) on LG6 was characterized by alleles associated with reduced flowering time in the northern temperate cultivar (Table 3). The qDTF.6-2 interval harbors 96 annotated genes including orthologs of the FTa1, FTa2, and FTc genes described previously in barrel clover and pea (Hecht et al., 2011; Supplemental Table S3). Similarly, Ortega et al. (2019) reported the presence of a cluster of FTa1, FTa2, and FTc under the peak of a major flowering time QTL on chickpea (Cicer arietinum L.) chromosome 3. In barrel clover and pea, significant roles have been reported for FTal based on analyses of induced mutants (Hecht et al., 2011; Laurie et al., 2011). Mutants of both species are late flowering under both long and short days and in barrel clover, transgenic overexpressing lines flower early with reduced photoperiod and vernalization requirements. The expression of MtFTal corresponds with conditions that promote flowering in barrel clover (Laurie et al.,
2011). MtFTal is up-regulated after a period of extended cold followed by exposures to warm, long-day photoperiods indicating that it integrates vernalisation and photoperiod signals.

In contrast, MtFTa2 is expressed at higher levels in short rather than long days and is upregulated during exposure to cold (Laurie et al., 2011). In pea, FTal gene corresponds to the GIGAS locus, which encodes a mobile floral signal that is essential for flowering under long days and promotes flowering under short days but is not required for the photoperiodic response (Hecht et al., 2011). There are inconsistent reports about the role of vernalization on flowering in lentil. Summerfield et al. (1985b) evaluated the effects of temperature and photoperiod on six lentil genotypes and reported that all flowered sooner when grown from vernalized seeds, but genotypes differed in their relative sensitivities. On the other hand, Roberts et al. (1988) used two lentil genotypes, one of which was also used in Summerfield et al. (1985b) and reported no evidence of vernalization response in either cultivar. The FTa homologue in lentil may or may not be involved with vernalization response; however, at both Rosthern and Sutherland, night temperatures were around or below freezing for several days after sowing and the vernalization requirements of seeds, if any, would have been met. Unlike FTa and FTb, which are expressed in leaves, FTc is only expressed in the shoot apex and plays a role in integration of signals from leafexpressed FT genes (Hecht et al., 2011; Laurie et al., 2011). In chickpea, elevated expression of FTal and FTc were consistently noticed in early flowering parents before floral induction under both short and long days but FTa2 transcript was not detected in some of the early parents, suggesting that FTal and $F T c$ are the likely candidates underlying their flowering time QTL (Ortega et al., 2019). Moreover, transgenic overexpression of barrel clover and pea FTa2 gene in Arabidopsis $f t-1$ mutants showed weak activity to induce flowering compared with FTal and FTc (Hecht et al., 2011; Laurie et al., 2011). This evidence suggests that both FTal and FTc are the likely candidate genes at $q D T F .6-2$ but it is also possible that the lentil FT genes have different expression or function.

Previous reports of QTL associated with flowering time have linked one gene, $S n$, to a seed coat pattern gene $(S c p)$ (Fratini et al., 2007; Kahriman et al., 2015; Sarker et al., 1999). Sn was later revealed to be an ELF3 ortholog (Weller et al., 2012) and it is found on chromosome 3 of the lentil reference assembly (Ramsay et al., 2021), so is not one of the genes responsible for variation in DTF in our study. Using a cross between a lentil cultivar and a $L$. orientalis (Boiss.) Hand.-Mazz. genotype, Fratini et al. (2007) indicated linkage between a flowering QTL and seed coat pattern locus, which led the authors to speculate that $S n$ was responsible. Fedoruk et al. (2013), however, mapped a seed coat pattern locus on chromosome 6. There were no DTF QTL near this locus in their temperate $\times$ temperate population. Using a cross between a lentil cultivar and a L. odemensis Ladiz. 
accession grown in a short-day environment, Polanco et al. (2019) reported a major QTL for flowering time on chromosome 6 that explained $56 \%$ of the observed variability. They also mapped a seed coat pattern locus nearby. Recently, our group identified a marker associated with seed coat pattern in a lentil diversity panel that maps to $12,192,948$ bp region of chromosome 6 in the lentil reference genome (Wright \& Bett, unpublished data, 2021). This suggests that the major flowering time QTL reported in Polanco et al. (2019) and qDTF.6-1 identified in our study are likely the same, and FTb may have a role in controlling flowering in both the long-day and short-day growing environments. Given that there are at least two loci involved in seed coat pattern and the one on chromosome 6 is not linked to $S n$, caution should be taken in interpreting the genetics of flowering time based on seed coat pattern. In pea, there are several known genes related to seed coat pattern (Blixt, 1974). One, the marbling locus Marmoreus $(\mathrm{M})$, is located near the High response $(\mathrm{Hr})$ flowering time gene (Murfet, 1973). The identity of pea $\mathrm{Hr}$ and lentil Sn as orthologs of ELF3 (Weller et al., 2012) suggests that the lentil Scp locus linked to $S n$ (Sarker et al., 1999) likely corresponds to the pea $M$, or possibly $F$, locus. Another pea locus, $F s$, maps to a genomic region that is syntenic with the top of lentil chromosome 6 (Lamprecht, 1942a, 1942b, 1948; Sindhu et al., 2014), and could be the ortholog of the second lentil pattern gene.

A single major QTL on LG5 was shown to affect REP, DTM, and DTS in LR-01 (Table 3). This region is clearly important for controlling postflowering developmental processes in lentil. The northern temperate cultivar contributed the alleles at this locus that delayed REP, DTM, and DTS (Table 3). This QTL interval harbors 561 annotated genes, which included, among others, embryonic abundant proteins, dehydration-responsive element-binding protein, and senescence-associated proteins. There are several potentially phenology- or senescence-associated genes in this broad interval and further research is required to narrow down the list.

Matching crop phenology to the growing environment is essential. In general, pulse breeding programs characterize breeding material by scoring DTF to identify lines that flower within the optimum window because measurement of DTM can be unreliable due to the occurrence of disease and adverse environmental conditions late into the growing season (Tullu et al., 2008). Availability of robust and predictive markers enhances the precision of identifying locally adapted germplasm. In spring-summer cropping systems of the temperate regions, where temperature and photoperiodic requirements for floral induction are met early in the season, lentil breeding programs should consider selecting for the late alleles at $q D T F .6-1, q D T F .6-2$, and $q D T M .5$. This ensures that plants flower within the optimum window after accumulation of sufficient biomass leading to greater yield. In winter cropping systems, such as Mediterranean and subtropi- cal savannah production regions, photoperiodic and temperature requirements for flowering are met slowly as the season progresses but lentil production is limited by high temperature and terminal drought in spring and early summer (Nelson et al., 2010). Early flowering is a desirable trait in these environments and the early allele at these QTL may be worth pursuing. In our study, DTF showed weak positive correlations with DTM across environments (Table 2). Early flowering leads to early onset of reproductive growth but genotypes that flower early did not necessarily mature early and genotypes that flower late can have a short reproductive period and mature together with the ones that flowered within the optimum window. Therefore, combined selection for DTF and DTM at the QTL identified in our study would enable accurate prediction of genotypes that are adapted to a particular environment.

In summary, QTL for key phenological traits in lentil were located using a RIL population derived from a cross between an exotic landrace and adapted cultivar. Two regions on LG6 harbored flowering-related QTL. Similarly, a stable region on LG5 was consistently associated with postflowering developmental processes. The flowering time QTL were validated in a different genetic background indicating their importance in other crosses between adapted and exotic germplasm. The peak markers linked to the QTL fell either within the gene coding sequences or close to known genes controlling flowering time and senescence and can be used for marker-assisted breeding to transfer desirable alleles from exotic germplasm into elite lentil cultivars.

\section{ACKNOWLEDGMENTS}

This research was conducted as part of the "Application of Genomics to Innovation in the Lentil Economy (AGILE)", a project funded by Genome Canada and managed by Genome Prairie. We are grateful for the matching financial support from the Saskatchewan Pulse Growers, Western Grains Research Foundation, the Government of Saskatchewan, and the University of Saskatchewan. We acknowledge the technical assistance of the bioinformatics, field and molecular lab staff of the Pulse Crop Breeding and Genetics group at the University of Saskatchewan.

\section{AUTHOR CONTRIBUTIONS}

TAH investigation, data curation, formal analysis, methodology, visualization, writing original draft, writing review \& editing. RS validation, writing review \& editing. JLW writing review \& editing. KEB conceptualization, funding acquisition, project administration, resources, supervision, writing review \& editing. All authors read and approved the submitted version.

\section{CONFLICT OF INTEREST}

The authors declare that they have no conflict of interest. 


\section{O R C I D}

Teketel A. Haile (D) https://orcid.org/0000-0002-6212-9489

James L. Weller (1) https://orcid.org/0000-0003-2423-8286

Kirstin E. Bett @ https://orcid.org/0000-0001-7959-6959

\section{R E F E R E N C E S}

Abe, M. (2005). FD, a bZIP protein mediating signals from the floral pathway integrator FT at the shoot apex. Science, 309, 1052-1056. https://doi.org/10.1126/science.1115983

Ahmad, M., McNeil, D. L., Fautrier, A. G., Armstrong, K. F., \& Paterson, A. M. (1996). Genetic relationships in Lens species and parentage determination of their interspecific hybrids using RAPD markers. Theoretical \& Applied Genetics, 92, 1091-1098. https://doi.org/10. 1007/BF00224054

Amasino, R. M., \& Michaels, S. D. (2010). The timing of flowering. Plant Physiology, 154, 516-520. https://doi.org/10.1104/pp.110. 161653

Andrés, F., \& Coupland, G. (2012). The genetic basis of flowering responses to seasonal cues. Nature Reviews Genetics, 13, 627-639. https://doi.org/10.1038/nrg3291

Blixt, S. (1974). The Pea. In R. C. King (Ed.), Handbook of genetics (pp. 181-221). Springer. https://doi.org/10.1007/978-1-4684-2994-7_9

FAO. (2020). Crop statistics. http://www.fao.org/faostat/en/\#data/QC

Federer, W. T. (1961). Augmented designs with one-way elimination of heterogeneity. Biometrics, 17, 447-473. https://doi.org/10.2307/ 2527837

Fedoruk, M. J., Vandenberg, A., \& Bett, K. E. (2013). Quantitative trait loci analysis of seed quality characteristics in lentil using single nucleotide polymorphism markers. The Plant Genome, 6. https:// doi.org/10.3835/plantgenome2013.05.0012

Fowler, S. (1999). GIGANTEA: A circadian clock-controlled gene that regulates photoperiodic flowering in Arabidopsis and encodes a protein with several possible membrane-spanning domains. EMBO Journal, 18, 4679-4688. https://doi.org/10.1093/emboj/18.17.4679

Fratini, R., Durán, Y., García, P., \& Pérez De La Vega, M. (2007). Identification of quantitative trait loci (QTL) for plant structure, growth habit and yield in lentil. Spanish Journal of Agricultural Research, 5, 348-356. https://doi.org/10.5424/sjar/2007053-255

Fratini, R. M., Pérez de la Vega, M., \& Sánchez, M. L. R. (2014). Lentil. In M. Singh, I. S. Bisht, \& M. Dutta (Eds.), Broadening the genetic base of grain legumes (p. 115-147). Springer. https://doi.org/ 10.1007/978-81-322-2023-7

Gaur, P. M., Samineni, S., Tripathi, S., Varshney, R. K., \& Gowda, C. L. L. (2015). Allelic relationships of flowering time genes in chickpea. Euphytica, 203, 295-308. https://doi.org/10.1007/ s10681-014-1261-7

Hecht, V., Foucher, F., Ferrándiz, C., Macknight, R., Navarro, C., Morin, J., Vardy, M. E., Ellis, N., Beltrán, J. P., Rameau, C., \& Weller, J. L. (2005). Conservation of Arabidopsis flowering genes in model legumes. Plant Physiology, 137, 1420-1434. https://doi.org/10.1104/ pp.104.057018

Hecht, V., Laurie, R. E., Vander Schoor, J. K., Ridge, S., Knowles, C. L., Liew, L. C., Sussmilch, F. C., Murfet, I. C., Macknight, R. C., \& Weller, J. L. (2011). The pea GIGAS gene is a FLOWERING LOCUS $T$ homolog necessary for graft-transmissible specification of flowering but not for responsiveness to photoperiod. The Plant Cell, 23, 147161. https://doi.org/10.1105/tpc. 110.081042
Hegde, V. S. (2010). Genetics of flowering time in chickpea in a semiarid environment. Plant Breeding, 129, 683-687. https://doi.org/10. 1111/j.1439-0523.2009.01748.x

Holland, J. B., Nyquist, W. E., \& Cervantes-Martínez, C. T. (2003). Estimating and interpreting heritability for plant breeding: An update. In J. Janick (Ed.), Plant breeding reviews (p. 9-112). John Wiley \& Sons. https://doi.org/10.1002/9780470650202.ch2

Imaizumi, T., Tran, H. G., Swartz, T. E., Briggs, W. R., \& Kay, S. A. (2003). FKF1 is essential for photoperiodic-specific light signalling in Arabidopsis. Nature, 426, 302-306. https://doi.org/10. 1038/nature02090

Jighly, A., Joukhadar, R., \& Alagu, M. (2015). SimpleMap: A pipeline to streamline high density linkage map construction. The Plant Genome, 8. https://doi.org/10.3835/plantgenome2014.09.0056

Kahriman, A., Temel, H. Y., Aydogan, A., \& Tanyolac, B. M. (2015). Major quantitative trait loci for flowering time in lentil. Turkish Journal of Agriculture \& Forestry, 38, 588-595. https://doi.org/10.3906/ tar-1408-16

Kardailsky, I. (1999). Activation tagging of the floral inducer FT. Science, 286, 1962-1965. https://doi.org/10.1126/science.286.5446. 1962

Kenward, M. G., \& Roger, J. H. (1997). Small sample inference for fixed effects from restricted maximum likelihood. Biometrics, 53, 983-997. https://doi.org/10.2307/2533558

Khazaei, H., Caron, C. T., Fedoruk, M., Diapari, M., Vandenberg, A., Coyne, C. J., McGee, R., \& Bett, K. E. (2016). Genetic diversity of cultivated lentil (Lens culinaris Medik.) and its relation to the world's agro-ecological zones. Frontiers in Plant Science, 7, 1093. https://doi. org/10.3389/fpls.2016.01093

Kobayashi, Y. (1999). A pair of related genes with antagonistic roles in mediating flowering signals. Science, 286, 1960-1962. https://doi. org/10.1126/science.286.5446.1960

Kong, F., Liu, B., Xia, Z., Sato, S., Kim, B. M., Watanabe, S., Yamada, T., Tabata, S., Kanazawa, A., Harada, K., \& Abe, J. (2010). Two coordinately regulated homologs of FLOWERING LOCUS T are involved in the control of photoperiodic flowering in soybean. Plant Physiology, 154, 1220-1231. https://doi.org/10.1104/pp.110.160796

Kosambi, D. D. (1943). The estimation of map distances from recombination values. Annals of Eugenics, 12, 172-175. https://doi.org/10. 1111/j.1469-1809.1943.tb02321.x

Kumar, J., \& Van Rheenen, H. A. (2000). A major gene for time of flowering in chickpea. Journal of Heredity, 91, 67-68. https://doi.org/10. 1093/jhered/91.1.67

Lamprecht, H. (1942a). Die Koppelungsgruppe Gp-Cp-Fs-Ast von Pisum. Hereditas, 28, 143-156. https://doi.org/10.1111/j.1601-5223. 1942.tb03271.x

Lamprecht, H. (1942b). Genstudien an Pisum sativum. V. Multiple Allele für Punktierung der Testa: Fsex-Fs-fs. Hereditas, 28, 157-164. https://doi.org/10.1111/j.1601-5223.1942.tb03272.x

Lamprecht, H. (1948). The variation of linkage and the course of crossing over. Agri Hortique Genetica, 6, 10-48.

Laurie, R. E., Diwadkar, P., Jaudal, M., Zhang, L., Hecht, V., Wen, J., Tadege, M., Mysore, K. S., Putterill, J., Weller, J. L., \& Macknight, R. C. (2011). The Medicago FLOWERING LOCUS Thomolog, MtFTal, is a key regulator of flowering time. Plant Physiology, 156, 22072224. https://doi.org/10.1104/pp.111.180182

Lin, X., Liu, B., Weller, J. L., Abe, J., \& Kong, F. (2021). Molecular mechanisms for the photoperiodic regulation of flowering in soybean. 
Journal of Integrative Plant Biology, 63, 981-994. https://doi.org/10. 1111/jipb.13021

Littell, R. C., Milliken, G. A., Stroup, W. W., \& Wolfinger, R. D. (2006). SAS system for mixed models (2nd ed.). SAS Institute Inc.

Lombardi, M., Materne, M., Cogan, N. O. I., Rodda, M., Daetwyler, H. D., Slater, A. T., Forster, J. W., \& Kaur, S. (2014). Assessment of genetic variation within a global collection of lentil (Lens culinaris Medik.) cultivars and landraces using SNP markers. BMC Genetics, 15, 150. https://doi.org/10.1186/s12863-014-0150-3

Lorieux, M. (2012). MapDisto: Fast and efficient computation of genetic linkage maps. Molecular Breeding, 30, 1231-1235. https://doi.org/ 10.1007/s11032-012-9706-y

Materne, M., \& Siddique, K. H. M. (2009). Agroecology and crop adaptation. In W. Erskine, F. J. Muehlbauer, A. Sarker, \& B. Sharma (Eds.), The lentil: Botany, production and uses (p. 47-63.). CAB International.

Murfet, I. C. (1973). Flowering in Pisum. Hr, a gene for high response to photoperiod. Heredity, 31, 157-164. https://doi.org/10.1038/hdy. 1973.72 https://doi.org/10.1038/hdy.1973.72

Nelson, M. N. (2010). Flowering time control in annual legumes: Prospects in a changing global climate. CAB Reviews, 5, 1-14. https:// doi.org/10.1079/PAVSNNR20105017

Ogutcen, E., Ramsay, L., Von Wettberg, E. B., \& Bett, K. E. (2018). Capturing variation in Lens (Fabaceae): Development and utility of an exome capture array for lentil. Applications in Plant Sciences, 6, e1165. https://doi.org/10.1002/aps3.1165

Ortega, R., Hecht, V. F. G., Freeman, J. S., Rubio, J., Carrasquilla-Garcia, N., Mir, R. R., Penmetsa, R. V., Cook, D. R., Millan, T., \& Weller, J. L. (2019). Altered expression of an FT cluster underlies a major locus controlling domestication-related changes to chickpea phenology and growth habit. Frontiers in Plant Science, 10, 824. https://doi.org/10. 3389/fpls.2019.00824

Polanco, C., Sáenz De Miera, L. E., González, A. I., García, P., Fratini, R., Vaquero, F., Vences, F. J., \& Pérez De La Vega, M. (2019). Construction of a high-density interspecific (Lens culinaris x L. odemensis) genetic map based on functional markers for mapping morphological and agronomical traits, and QTLs affecting resistance to Ascochyta in lentil. PLoS ONE, 14, e0214409. https://doi.org/10. 1371/journal.pone.0214409

Putterill, J., Robson, F., Lee, K., Simon, R., \& Coupland, G. (1995). The CONSTANS gene of Arabidopsis promotes flowering and encodes a protein showing similarities to zinc finger transcription factors. Cell, 80, 847-857. https://doi.org/10.1016/0092-8674(95)90288-0

Ramsay, L., Koh, C. S., Kagale, S., Gao, D., Kaur, S., Haile, T., Gela, T. S., Chen, L., Cao, Z., Konkin, D. J., Toegelová, H., Doležel, J., Rosen, B. D., Stonehouse, R., Humann, J. L., Main, D., Coyne, C. J., McGee, R. J., Cook, D. R., Penmetsa, R. V., Vandenberg, A., Chan, C., Banniza, S., Edwards, D., Bayer, P. E., Batley, J., Udupa, S. M., $\&$ Bett, K. E. (2021). Genomic rearrangements have consequences for introgression breeding as revealed by genome assemblies of wild and cultivated lentil species. BioRxiv. https://doi.org/10.1101/2021. 07.23.453237

Roberts, E. H., Summerfield, R. J., Ellis, R. H., \& Stewart, K. A. (1988). Photothermal time for flowering in lentils (Lens culinaris) and the analysis of potential vernalization responses. Annals of Botany, 61, 29-39. https://doi.org/10.1093/oxfordjournals.aob.a087525

Roberts, E. H., Summerfield, R. J., Muehlbauer, F. J., \& Short, R. W. (1986). Flowering in lentil (Lens culinaris Medic.): The duration of the photoperiodic inductive phase as a function of accumulated daylength above the critical photoperiod. Annals of Botany, 58, 235248. https://doi.org/10.1093/oxfordjournals.aob.a087201

Sarker, A. (1999). Inheritance and linkage relationship of days to flower and morphological loci in lentil (Lens culinaris Medikus subsp. culinaris). Journal of Heredity, 90, 270-275. https://doi.org/10.1093/ jhered/90.2.270

Searle, I., He, Y., Turck, F., Vincent, C., Fornara, F., Kröber, S., Amasino, R. A., \& Coupland, G. (2006). The transcription factor FLC confers a flowering response to vernalization by repressing meristem competence and systemic signaling in Arabidopsis. Genes \& Development, 20, 898-912. https://doi.org/10.1101/gad.373506

Simpson, G. G. (2004). The autonomous pathway: Epigenetic and posttranscriptional gene regulation in the control of Arabidopsis flowering time. Current Opinion in Plant Biology, 7, 570-574. https://doi.org/ 10.1016/j.pbi.2004.07.002

Sindhu, A., Ramsay, L., Sanderson, L. A., Stonehouse, R., Li, R., Condie, J., Shunmugam, A. S. K., Liu, Y., Jha, A. B., Diapari, M., Burstin, J., Aubert, G., Tar'an, B., Bett, K. E., Warkentin, T. D., \& Sharpe, A. G. (2014). Gene-based SNP discovery and genetic mapping in pea. Theoretical \& Applied Genetics, 127, 2225-2241. https://doi.org/10. 1007/s00122-014-2375-y

Suárez-López, P., Wheatley, K., Robson, F., Onouchi, H., Valverde, F., \& Coupland, G. (2001). CONSTANS mediates between the circadian clock and the control of flowering in Arabidopsis. Nature, 410, 11161120. https://doi.org/10.1038/35074138

Summerfield, R. J., Muehlbauer, F. J., \& Roberts, E. H. (1985a). Lens culinaris. In A. H. Halevy (Ed.), Handbook of flowering (Vol. 1, p. 118-124). CRC.

Summerfield, R. J., Roberts, E. H., Erskine, W., \& Ellis, R. H. (1985b). Effects of temperature and photoperiod on flowering in lentils (Lens culinaris Medic.). Annals of Botany, 56, 659-671. https://doi.org/10. 1093/oxfordjournals.aob.a087055

Tullu, A., Diederichsen, A., Suvorova, G., \& Vandenberg, A. (2011). Genetic and genomic resources of lentil: Status, use and prospects. Plant Genetic Resources, 9, 19-29. https://doi.org/10. 1017/S1479262110000353

Tullu, A., Tar'an, B., Warkentin, T., \& Vandenberg, A. (2008). Construction of an intraspecific linkage map and QTL analysis for earliness and plant height in lentil. Crop Science, 48, 2254-2264. https://doi.org/10.2135/cropsci2007.11.0628

Vandenberg, A., Banniza, S., Warkentin, T. D., Ife, S., Barlow, B., Mchale, S., Brolley, B., Gan, Y., Mcdonald, C., Bandara, M., \& Dueck, S. (2006). CDC Redberry lentil. Canadian Journal of Plant Science, 86, 497-498. https://doi.org/10.4141/P05071

Vandenberg, A., Kiehn, F. A., Vera, C., Gaudiel, R., Buchwaldt, L., Dueck, S., Wahab, J., \& E Slinkard, A. (2002). CDC Robin lentil. Canadian Journal of Plant Science, 82, 111-112. https://doi.org/10. 4141/P01-003

Wang, S., Basten, C. J., \& Zeng, Z. B. (2012). Windows QTL Cartographer 2.5. North Carolina State University. http://statgen.ncsu.edu/ qtlcart/WQTLCart.htm

Weller, J. L., Liew, L. C., Hecht, V. F. G., Rajandran, V., Laurie, R. E., Ridge, S., Wenden, B., Vander Schoor, J. K., Jaminon, O., Blassiau, C., Dalmais, M., Rameau, C., Bendahmane, A., Macknight, R. C., \& Lejeune-Henaut, I. (2012). A conserved molecular basis for photoperiod adaptation in two temperate legumes. Proceedings of the National Academy of Sciences of the United States of America, 109, 21158-21163. https://doi.org/10.1073/pnas. 1207943110 
Weller, J. L., \& Ortega, R. (2015). Genetic control of flowering time in legumes. Frontiers in Plant Science, 6, 207. https://doi.org/10.3389/ fpls. 2015.00207

Wigge, P. A. (2005). Integration of spatial and temporal information during floral induction in Arabidopsis. Science, 309, 1056-1059. https://doi.org/10.1126/science.1114358

Wolfinger, R., Federer, W. T., \& Cordero-Brana, O. (1997). Recovering information in augmented designs, using SAS PROC GLM and PROC MIXED. Agronomy Journal, 89, 856-859. https://doi.org/10. 2134/agronj1997.00021962008900060002x

Wright, D. M., Neupane, S., Heidecker, T., Haile, T. A., Chan, C., Coyne, C. J., McGee, R. J., Udupa, S., Henkrar, F., Barilli, E., Rubiales, D., Gioia, T., Logozzo, G., Marzario, S., Mehra, R., Sarker, A., Dhakal, R., Anwar, B., Sarkar, D., .. Bett, K. E. (2021). Understanding photothermal interactions will help expand production range and increase genetic diversity of lentil (Lens culinaris Medik.). Plants, People, Planet, 3, 171-181. https://doi.org/10.1002/ppp3.10158

Wu, Y., Bhat, P. R., Close, T. J., \& Lonardi, S. (2008). Efficient and accurate construction of genetic linkage maps from the minimum spanning tree of a graph. PLoS Genetics, 4, e1000212. https:// doi.org/10.1371/journal.pgen.1000212
Yamashino, T., Yamawaki, S., Hagui, E., Ueoka-Nakanishi, H., Nakamichi, N., Ito, S., \& Mizuno, T. (2013). Clock-controlled and FLOWERING LOCUS T (FT)-dependent photoperiodic pathway in Lotus japonicus I: Verification of the flowering associated function of an FT homolog. Bioscience, Biotechnology, \& Biochemistry, 77, 747-753. https://doi.org/10.1271/bbb.120871

\section{SUPPORTING INFORMATION}

Additional supporting information may be found in the online version of the article at the publisher's website.

How to cite this article: Haile, TA, Stonehouse, $\mathrm{R}$, Weller, JL, \& Bett, KE. Genetic basis for lentil adaptation to summer cropping in northern temperate environments. Plant Genome. 2021;e20144.

https://doi.org/10.1002/tpg2.20144 